\title{
Activities of some metabolic enzymes in the small intestinal mucosa during pregnancy and lactation in the rat
}

\author{
Maureen F. Palmer* and B. A. Rolls \\ National Institute for Research in Dairying, Shinfield, Reading RG2 9AT, Berkshire, U.K.
}

\begin{abstract}
Summary. The food intake, gut weight, gut length, mucosal protein and mucosal activities of alkaline phosphate (EC 3.1.3.1), acid phosphate (EC 3.1.3.2), isocitric dehydrogenase (EC 1.1.1.42) and glucose-6-phosphate (EC 3.1.3.9) were measured in rats during pregnancy, lactation and after the young were weaned. In general, the quantities measured increased slightly during pregnancy and considerably during lactation, reaching maximum values during the 3rd week of lactation and falling more or less rapidly after the young were weaned to the same levels as those in unmated animals. However, the gut length and mucosal protein remained higher even 3 weeks after weaning, so that weight per unit length and specific enzyme activities (per mg protein) tended to be lower in mated than in unmated rats. Changes in the specific activities of enzymes indicate alterations of the metabolic function of the enterocytes during breeding similar to changes reported for digestive enzymes. It is suggested that the intestine may reflect changes that take place in the liver.
\end{abstract}

\section{Introduction}

Some of the changes produced by pregnancy and lactation in various extra-reproductive organs have been reviewed by Fell (1977) and Rolls, Henschel \& Palmer (1979). In particular, we have shown that the activities of some enzymes responsible for protein digestion are increased in the small intestine (Rolls, 1975) and in the pancreas (Rolls et al., 1979), slightly in pregnancy and markedly during lactation. In the present experiments, 4 metabolic enzymes were studied to investigate whether their activities alter during the reproductive cycle and whether any changes can be related to the general gastrointestinal enlargement or to the variations in digestive capacity.

The 4 enzymes studied were chosen as representing different locations in the cell. Alkaline phosphatase (EC 3.1.3.1) is in the brush border and acid phosphatase (EC 3.1.3.2) is lysosomal. Isocitric dehydrogenase activity (EC 1.1.1.42, NADP-dependent) is represented by two enzymes located in the mitochondria and cytosol or by one enzyme distributed between the two, whereas glucose-6-phosphatase (EC 3.1.3.9) is located in the endoplasmic reticulum. The precise metabolic functions of these enzymes in the cell are debated, but recent work suggests the following roles. Alkaline phosphatase may be associated with the transport of nutrients across and the transfer of energy within the microvillar membrane of the absorptive surface (Fernley, 1971), and acid phosphatase may be involved in the provision of energy for organelle destruction. It has been suggested that the NAD-dependent isocitric dehydrogenase (EC 1.1.1.41) is responsible for the respiratory chain-linked oxidation of citrate under normal conditions whereas the NADP-dependent enzyme may function under conditions of high energy

* Present address: Department of Physiology, Queen Elizabeth College, University of London, Campden Hill Road, London W8 7AH, U.K. 
demand or in biosynthetic or control processes (Stein, Stein \& Kirkman, 1967; Garland, 1968). Smith \& Plaut (1979) have discussed the relative importance of the two enzymes to citric acid cycle oxidation. The major sites of activity of glucose-6-phosphatase are in the liver, kidney and small intestine. In the liver and the kidney it functions in the terminal stage of gluconeogenesis, but the absence of some enzymes from this pathway in the intestine suggests a different role in this organ (Lygre \& Nordlie, 1968). There is a common genetic identity of the enzyme in the three tissues and, although it has been suggested that in the intestine it may be involved in a special mechanism for glucose absorption which is insulin-insensitive, since its activity is markedly affected by induced diabetes and fasting, it may respond to changes in insulin secretion, through which we have suggested that the changes in extra-reproductive organs during pregnancy and lactation may be mediated.

\section{Materials and Methods}

Chemicals. Laboratory chemicals were of Analar grade. Glucose-6-phosphoric acid, dipotassium salt, and Folin-Ciocalteu reagent were supplied by BDH Ltd., Dorset, and other enzymes, enzyme substrates and biochemicals were bought from Sigma (London) Chemical Co., Poole, Dorset.

\section{Animals}

Female Norwegian Hooded rats, 4-5 months old, from the Institute colony were used. To ensure that the stage of pregnancy was known, vaginal smears were examined to detect the stage of oestrus so that matings could be timed. The presence of spermatozoa in subsequent smears was taken to indicate impregnation and the state of pregnancy was checked at the end of the experiment. For lactating and post-weaning animals, the rats were mated at intervals and the date of parturition was noted. Litter size varied between 6 and 10 . The rats were given a commercial laboratory diet (Spratts Laboratory Diet 1) and were allowed unrestricted access to food and water throughout. The food consumptions were measured in the $24 \mathrm{~h}$ immediately before killing the rat.

At weekly intervals from the end of the 1st week of pregnancy to the end of the $3 \mathrm{rd}$ week after the young were weaned, rats were taken at the same time of day without prior fasting. They were anaesthetized with diethyl ether, the gut was exposed and the small intestine washed out from the pylorus to the ileocaecal junction with the minimum quantity of cold isotonic saline $(9 \mathrm{~g}$ $\mathrm{NaCl} / \mathrm{l})$. The small intestine was then removed and cooled on ice, and the rat was killed (09:0009:30 h).

The intestine was rapidly weighed and its length measured under standard tension provided by a $10 \mathrm{~g}$ weight; it was then returned to the ice-bath and cut lengthways. The mucosa was removed by gentle scraping with a glass slide and disrupted in ice-cold $0.1 \mathrm{M}-\mathrm{NaCl}$ with ultrasonic vibrations (Dawe Instruments, Western Avenue, London W3 OSD). The extract was prepared by stirring the homogenate for $60 \mathrm{~min}$ in an ice-bath, straining through cheesecloth and adjusting the volume to $50 \mathrm{ml}$. A $20 \mathrm{ml}$ aliquot was mixed with an equal volume of $n$-butanol and stirred for a further $60 \mathrm{~min}$ over ice. Both the saline and the saline-butanol extracts were centrifuged at $4500 \mathrm{~g}$ at $0-5^{\circ} \mathrm{C}$ to remove debris and the saline-butanol extract was dialysed against distilled water at $0-4^{\circ} \mathrm{C}$ for at least $24 \mathrm{~h}$. Both extracts were stored at $-20^{\circ} \mathrm{C}$ until analysis.

\section{Analysis and measurement of enzyme activities}

The protein content of the gut mucosa was measured by the method of Lowry, Rosebrough, Farr \& Randall (1951) using the Folin-Ciocalteu reagent. The activity of isocitric 
dehydrogenase in the mucosa was estimated by a method adapted from the work of Ochoa

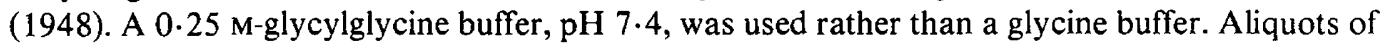
the saline homogenate were added to a freshly prepared 'mixed substrate' of isocitric acid, NADP, buffer and activating $\mathrm{MnCl}_{2}$ and the change in optical density at $340 \mathrm{~nm}$ was monitored over a $70 \mathrm{sec}$ period. Estimation of glucose-6-phosphatase was based on the method of Swanson (1955), except that a $0.01 \mathrm{M}$-EDTA buffer of $\mathrm{pH} 6.5$ was used in place of the maleic acid buffer. After incubation of the saline homogenate and substrate, inorganic phosphate was measured by the method of Allen (1940) which is a slight modification of that of Fiske \& SubbaRow (1925). Acid and alkaline phosphatases were estimated by the method of Brandenberger \& Hanson (1953), using a 3.65 $\times 10^{-4} \mathrm{M}-0$-carboxyphenyl phosphate solution as a substrate and with Tris buffer replacing glycine buffer for the alkaline phosphatase. The saline extract was used for acid phosphatase determinations and the saline-butanol extract for the alkaline phosphatase. (The $n$-butanol treatment solubilizes the alkaline phosphatase which otherwise is firmly attached to lipoprotein membranes.)

\section{Statistical analyses}

The significance of differences between means was tested by Student's $t$ test.

\section{Results}

The results are given in Table 1. The control group of unmated animals was killed at intervals throughout the experiment, but no significant changes in any measurement with time were detected. The increases in food intake, about $35 \%$ during pregnancy and $350 \%$ in lactation, were consistent with those reported previously from this laboratory. The gut weight and the mucosal protein content, which rose approximately in proportion, showed patterns of change similar to those of food intake, with maximum values at the end of lactation and a sharp fall towards pre-impregnation levels after the young were weaned. However, the gut weight returned to a value not significantly different from the pre-impregnation figure although total protein remained about $40 \%$ higher. Moreover, the length of the gut, which also increased significantly during lactation, remained higher at 3 weeks after weaning.

The total alkaline phosphatase activities followed the 'standard' pattern: a slight, non-significant increase during pregnancy and a marked, statistically significant, rise during lactation, reaching a peak at the end of the 3rd week of lactation, with a rapid and complete return to pre-impregnation values after the young were weaned. Although total acid phosphatase activity reached a peak at the same time, increases were slower to develop and the activity was slow to return to the original value. Isocitric dehydrogenase activity had increased significantly by the end of pregnancy, was at a maximum during the 2 nd and 3 rd weeks of lactation, and fell relatively slowly after weaning. Glucose-6-phosphatase activity was also significantly higher in lactating than in non-pregnant rats, and increased during the 2 nd and 3 rd weeks after weaning although the value at the 1 st week after weaning was no higher than in unmated rats. Activity was reduced, though not significantly, in the 2 nd week of pregnancy.

The changes in specific activity (per mg protein) of alkaline and acid phosphatases during the reproductive cycle were not significant. However, that of isocitric dehydrogenase activity was significantly higher during lactation and that of glucose-6-phosphatase was significantly raised during lactation and at 3 weeks after weaning and significantly depressed in the 2 nd week of pregnancy. 


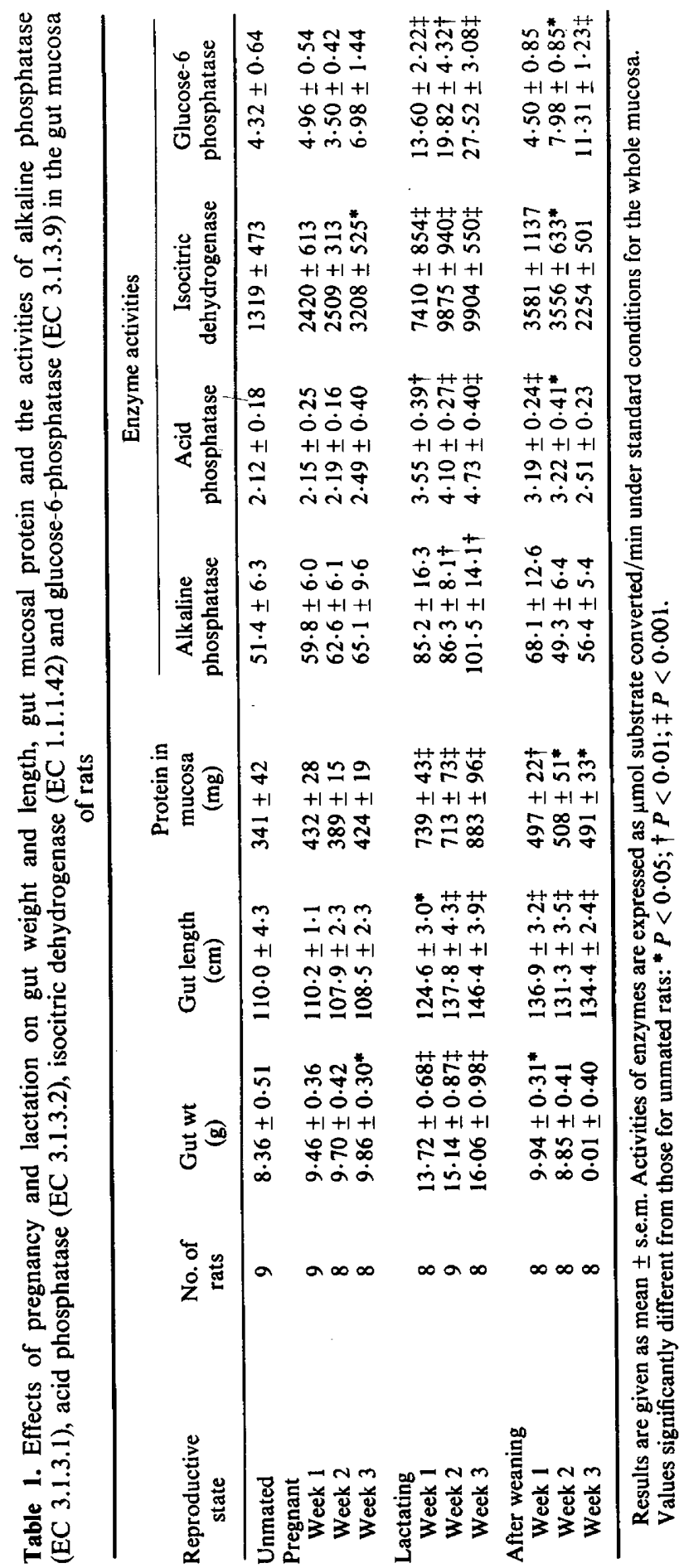




\section{Discussion}

The changes in gut weight, length and protein content were consistent with previous findings for rodents and ruminants. Although the rats whose young had been weaned had a similar food intake and probably similar nutrient requirements to those of the unmated rat, their small intestines remained significantly longer and had a significantly higher mucosal protein content, even though they were not heavier than those of their unmated counterparts. Unlike that of the non-pregnant rat, the intestine of the mated animal may have a lower proportion of connective tissue or the thickness or state of hydration of the muscle layers may have altered. It might be inferred from the similar food intake and probably similar nutrient needs of the unmated and post-weaning rats that these dimensional changes do not alter the overall digestive performance of the gut, but this was not investigated in these experiments.

There was a considerable variation in individual results, even among groups of unmated rats, although these differences were not significant. Such variation could be related to oestrogen levels, which are known to affect activities of metabolic enzymes, but the stage of the oestrous cycle was not determined in this work. Variation may also arise because of the slight differences in the age at which the rats were mated.

Higher total enzyme activities would be expected in the enlarged gut, but changes in specific activity may reflect adaptations in cellular metabolic activity resulting from hormonal or other influences. Discussion of these changes must be tentative in some respects because of uncertainty about their exact function (see 'Introduction').

The increase in alkaline phosphatase activity probably reflects the need for increased nutrient absorption, but since the specific activity was not significantly changed we assume that the increased total capacity merely reflected the increased mucosal cell population. If acid phosphatase is concerned in the turnover of cell organelles an increase proportional to the protein content and gut weight would be expected, but there was no increase in specific activity. The persistence of higher acid phosphatase activities after weaning may be an indication of a continued higher need for organelle destruction in the reversion of the gut to the state found in non-breeding animals.

If it is assumed that isocitric dehydrogenase and glucose-6-phosphatase are associated with energy production the increases in total activity observed presumably reflect the increased energy requirements of the enlarged intestine. There were also increases in specific activity, suggesting an adaptation of mucosal cells to changed conditions. Without further work it is not possible to tell whether the increases in isocitric dehydrogenase were mitochondrial or cytosolic, or both, but numbers of mitochondria may have been increased by higher levels of thyroxine, which is known to increase in lactation (Grosvenor \& Turner, 1958).

There was a fall in total and specific glucose-6-phosphatase activity in the 2nd week of pregnancy. It is tempting to envisage a connection between this and the fall in pancreas weight and proteolytic enzyme activity (Rolls et al., 1979), but if the pancreatic effect is the result of restricted nutrient availability it would seem improbable that such an explanation could apply to an intestinal enzyme activity, particularly as no other intestinal function investigated was altered.

After weaning there was a fall in the specific activity of alkaline phosphatase, and possibly of acid phosphatase, although the greater length of the post-weaning intestine (as compared with that of unmated rats) meant that the total enzyme activities were approximately the same as those in unmated animals. This situation is similar to that found with dipeptidases (Rolls, 1975) and leucine and glucose absorption (Cripps \& Williams, 1975). In contrast, the specific activity of isocitric dehydrogenase did not fall and that of glucose-6-phosphatase actually rose after a trough at 1 week after weaning, producing a considerable rise in total activity. The reason for this increased enzyme production at the 3 rd week after weaning is not clear.

These experiments show that some metabolic enzymes, like the digestive enzymes investigated in previous work (Rolls, 1975; Rolls etoal.9a1979), , increase during pregnancy and lactation in the rat and that, at least in some instances, these increases are in excess of those 
expected simply from enlargement of the gut. These changes in total activity can be contrasted with the findings of Burdett, Green \& Reek (1978) who studied a range of metabolic enzymes in different regions of the gut histochemically and reported some increases in activity during pregnancy but, in general, no further increases in lactation. Studies on some of the enzymes involved in energy production in the intestine by Burdett \& Reek (1979) provide valuable complementary evidence. While specific activities of some enzymes were unchanged, others varied during the reproductive cycle and Burdett \& Reek (1979) concluded that the response of the gut to the stimuli of pregnancy and lactation was complex. (Changes in the activity of NADP-dependent isocitric dehydrogenase, the only enzyme common to the two studies, were similar to those reported here.) Falls in total glucose-6-phosphatase activity in sheep liver (Mackie \& Campbell, 1972) and specific activity in rat liver (Smith, 1975) have been observed during pregnancy, results similar to those observed here in the gut. Moreover, glucose6-phosphatase in the liver is markedly affected by hormonal changes (Ashmore, Hastings, Neskett \& Renold, 1956). This raises the possibility that the intestine, in addition to its digestive and adsorptive roles, has a function as a metabolic organ, perhaps reflecting changes in the liver.

We thank Miss S. C. Woodley for technical assistance and Miss M. Tyler and her staff for care of the rats.

\section{References}

Allen, R.J.L. (1940) The estimation of phosphorus. Biochem. J. 34, 858-865.

Ashmore, J., Hastings, A.B., Neskett, F.B. \& Renold, A.E. (1956) Studies on carbohydrate metabolism in rat liver slices. VI. Hormonal factors influencing glucose-6-phosphatase. J. biol. Chem. 218, 77-88.

Brandenberger, H. \& Hanson, R. (1953) Eine spektrophotometrische Bestimmungsmethode für saure und alkalische Phosphatasen. Helv. Chim. Acta 36, 900-906.

Burdett, K. \& Reek, C. (1979) Adaptation of the small intestine during pregnancy and lactation in the rat. Biochem. J. 184, 245-251.

Burdett, K., Green, F. \& Reek, C. (1978) Enzyme changes in rat small intestine during pregnancy and lactation. Histochem. J. 10, 343-347.

Cripps, A.W. \& Williams, V.J. (1975) The effect of pregnancy and lactation on food intake, gastrointestinal anatomy and the absorptive capacity of the small intestine in the albino rat. Br. J. Nutr. 33, 17-32.

Fell, B.F. (1977) The gut in reproduction. Rep. Rowett Inst. 3, 97-107.

Fernley, H.N. (1971) Mammalian alkaline phosphatases. In The Enzymes, 3rd edn, Vol. 4, pp. 421-422. Ed. P. D. Boyer. Academic Press, New York.

Fiske, C.H. \& SubbaRow, Y. (1925) The colorimetric determination of phosphorus. J. biol. Chem. 66, $375-400$.

Garland, P.B. (1968) Control of citrate synthesis in mitochondria. In The Metabolic Roles of Citrate, $\mathrm{pp}$. 41-60. Ed. T. W. Goodwin. Academic Press, London.

Grosvenor, C.E. \& Turner, C.W. (1958) Effect of lactation upon thyroid secretion rate in the rat. Proc. Soc. exp. Biol. Med. 99, 517-519.

Lowry, O.H., Rosebrough, N.J., Farr, A.L. \& Randall, R.J. (1951) Protein measurement with the Folin phenol reagent. J. biol. Chem. 193, 265-275.
Lygre, D.G. \& Nordlie, R.C. (1968) Phosphohydrolase and phosphotransferase activity of intestinal glucose6-phosphatase. Biochemistry, Easton 7, 3219-3226.

Mackie, W.S. \& Campbell, R.M. (1972) Effects of pregnancy and lactation on the activities of pure gluconeogenic and urea-cycle enzymes in sheep liver. J. agric. Sci., Camb. 79, 423-429.

Ochoa, S. (1948) Biosynthesis of tricarboxylic acids by carbon dioxide fixation. III. Enzymatic mechanisms. J. biol. Chem. 174, 133-157.

Rolls, B.A. (1975) Dipeptidase activity in the small intestinal mucosa during pregnancy and lactation in the rat. Br. J. Nutr. 33, 1-9.

Rolls, B.A., Henschel, M.J. \& Palmer, M.E. (1979) The effects of pregnancy and lactation on the activities of trypsin and $\alpha$-chymotrypsin in the rat pancreas. $B r$. $J$. Nutr. 41, 573-578.

Smith, C.M. \& Plaut, G.W.E. (1979) Activities of NAD-specific and NADP-specific isocitrate dehydrogenases in rat-liver mitochondria. Eur.J. Biochem. 97, 283-295.

Smith, R.W. (1975) The effects of pregnancy and lactation on the activities in rat liver of some enzymes associated with glucose metabolism. Biochim. biophys. Acta 404, 22-29.

Stein, A.M., Stein, J.H. \& Kirkman, S.K. (1967) Diphosphopyridine nucleotide specific isocitric dehydrogenase of mammalian mitochondria. I. On the roles of pyridine nucleotide transhydrogenase and the isocitric dehydrogenases in the respiration of mitochondria of normal and neoplastic tissues. Biochemistry, Easton 6, 1370-1379.

Swanson, M.A. (1955) Glucose-6-phosphatase from liver. In Methods in Enzymology, Vol. 2, pp. 541-543. Eds S. P. Colowick \& N. O. Kaplan. Academic Press, New York. 